\title{
From the President of the International Union of Crystallography
}

W hen the Editor of Crystal Growth \& Design asked me to write a guest editorial in my capacity as President of the International Union of Crystallography (IUCr) I took some time in agreeing. On the one hand, the growth and development of the subjects of crystal engineering and crystal growth have depended heavily on crystallography in general and in particular on the various methods that have been used to determine the crystal structures of organic, inorganic, and metal-organic compounds. Also, I have been associated closely with CGD since its very inception and have watched with pleasure its rise to a position where it has become one of the leading forums for publication of original work in crystal engineering, quite apart from publishing many of my own papers in the journal. On the other hand, one of the main activities of the IUCr, indeed an activity that sets it apart from many other adhering organizations of the International Council of Scientific Union (ICSU), is that it is a noted publisher of scholarly journals for nearly 65 years. Our eight journals include some that have successfully published papers in the areas of crystal growth and crystal engineering. So I write this editorial both as a friend of CGD and also as a competitor.

IUCr was founded in the late 1940s primarily because of the wartime closure of the then dominant crystallographic journal Zeitschrift für Kristallographie and the perceived need for a journal that could publish outstanding crystallographic results worldwide. The fates of the IUCr and those of Acta Crystallographica have always been intertwined, and in the IUCr we are always very proud of the high quality of the crystallographic results reported in our journals. Crystal engineering has also relied on accurately determined crystal structures, and many practitioners of crystal engineering have approached this subject from a crystallographic viewpoint. Be this as it may, I feel that there is enough going on in the subject of crystal engineering at the present time that crystal engineers have not one but several journals in which they can publish their work. Acta Crystallographica Sections B, C, and E from the IUCr and CGD from the ACS are certainly some important journals where authors in this peer group may choose to publish their work. Papers with a higher crystallographic content such as those that report methodology advances be they in high pressure crystallography, cryocrystallography, charge density studies, computational crystal structure prediction, or the study of less ordered materials are also appropriate for the IUCr journals. The above-mentioned subjects are already quite important in the crystal engineering context. As crystal engineering turns its attention from structure to properties it will be quite interesting to see how the various specialist journals will do in the future. For authors, this is an advantageous situation because there seems to be no dearth of good journals where one may submit one's work.

Coming away from the journals, the IUCr promotes international cooperation in crystallography and acts as a focus for establishing relationships between crystallography and other sciences. The United Nations has declared 2014 to be the International Year of Crystallography (IYCr). I would like to invite CGD to mark IYCr by publishing special issues of papers where the crystallographic content is unusually important. Other journals not belonging to the IUCr family are already initiating such activities, and I would like to emphasize that IYCr is by no means a monopoly of IUCr. Readers of CGD should also note that IUCr has active programs of support for visiting professorships in various disadvantaged regions of the world.

Of special interest to structural and materials chemists are the activities of our commissions. Many of them (crystallographic computing, charge, spin and momentum densities, high pressure, neutron scattering, nomenclature, powder diffraction, structural chemistry, synchrotron radiation) are of particular interest to readers of CGD. The commission for crystallographic nomenclature and the commission for structural chemistry are currently working with IUPAC on a project that is concerned with the definition of terms in crystal engineering. I would ask readers and authors of CGD to interact with our commissions. The commissions are also responsible for sponsoring meetings and for suggesting names of speakers and microsymposium chairs in our own congresses. Another area where readers of CGD may interact with the IUCr is to suggest the names of nominees for the Ewald Prize, which is awarded by IUCr every triennium to a crystallographer of unusual eminence.

Recently IUCr has started a scheme where students and postdocs in the American, European, and Asian regions can attend meetings of the Regional Associates other than the one in which they live and work. Upcoming meetings are taking place in Hawaii, Warwick, and Adelaide, and I would like to ask all of you to take advantage of this scheme. Friends made when one is young become lifelong colleagues in academic life, and it is important to emphasize international collaboration in this time of globalization. CGD has always attracted a highly international and eclectic authorship, and this scheme seems to be particularly appropriate to readers of the journal.

As crystal engineering and crystal growth continue their growth and become mainstream subjects, I am sure that there will be a much closer association between the IUCr and CGD, and I wish Crystal Growth \& Design all success in its activities.

Gautam R. Desiraju, Guest Editor

Indian Institute of Science, Bangalore

\section{AUTHOR INFORMATION}

Notes

Views expressed in this editorial are those of the author and not necessarily the views of the ACS. 